\title{
A Modified Recovery Position
}

\author{
N Hussain, A Dobbie, KP Allison, M England, KM Porter
}

\section{Introduction}

There is a dilemma in pre-hospital care regarding the rapid yet safe movement of the unconscious patient by a single rescuer in order to protect airway and spine. Guidelines should be based around the lowest common denominators of patient safety and rescuer skill and various methods have been proposed. Few methods have been scientifically investigated in terms of spine distortion or patient comfort. Two modifications of existing methods of recovery position are proposed in order

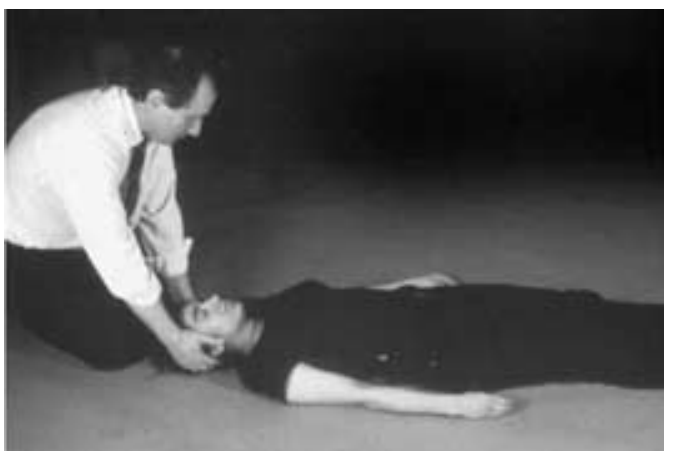

N Hussain MBChB Pre-registration house officer in Trauma \& Orthopaedics - UHBT

A Dobbie MBChB Senior house officer in A\&E - UHBT

Pre-hospital care doctor

KP Allison RCS(Eng) FRCS(Plast) FIMC RCS(Ed)

$\mathrm{SpR}$ in plastic surgery UHBT. Pre-hospital care doctor

Email: kallison@ukonline.co.uk

$M$ England RAMC

KM Porter RCS(Eng)

FRCS(Ed), FIMC

$\mathrm{RCS}(\mathrm{Ed})$

Consultant trauma surgeon - UHBT

Pre-hospital care doctor

Department of Plastic Surgery,

University Hospitals

Birmingham,

NHS Trust (UHBT),

Raddlebarn Road,

Birmingham, B29 6JD
Fig 1.

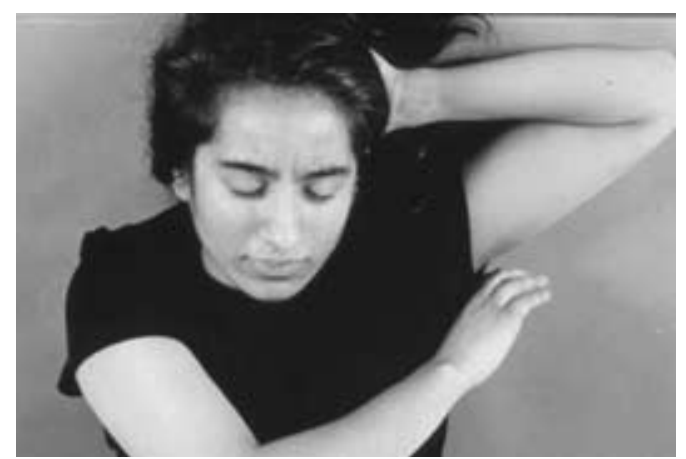

Fig 3.

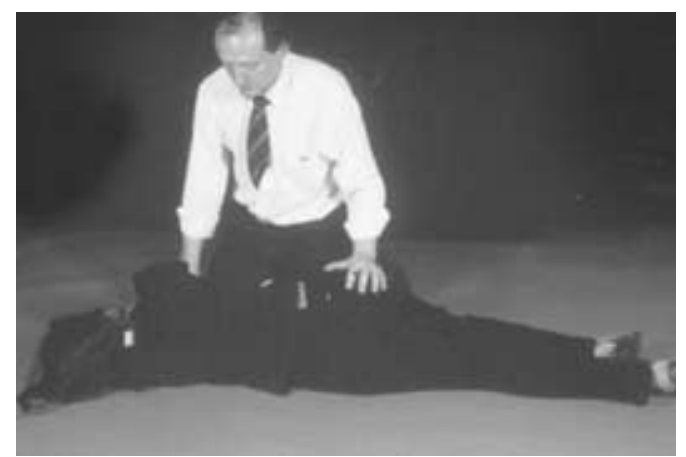

Fig 5. to turn a patient from either a supine or prone position. The senior authors use these in their pre-hospital practise and feel that they may warrant further evaluation.

\section{Method One}

This technique allows the rescuer to turn the patient from a supine position into lateral / semi-prone position. (For example when the patient is vomiting or when the airway is at risk from obstruction from other foreign debris such as blood and conventional suction methods are not available).

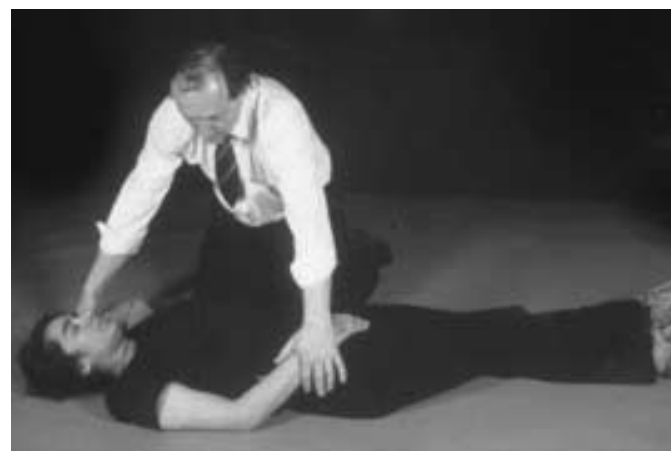

Fig 2.

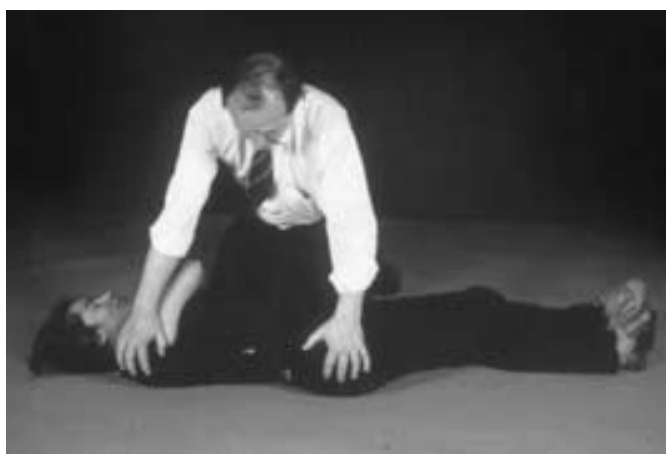

Fig 4.

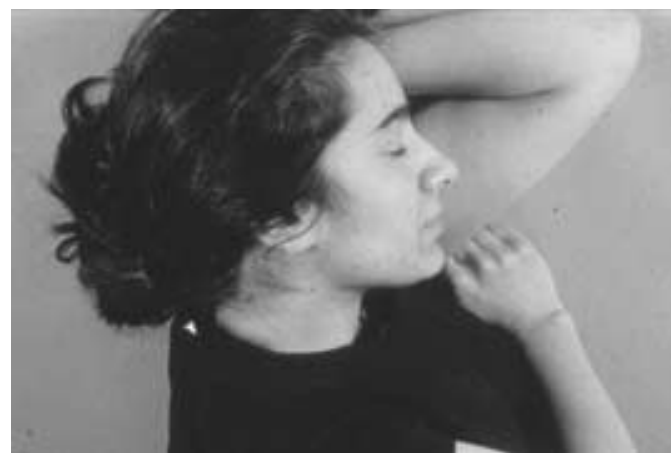

Fig 5. 
Figure 1. Initial position, allowing airway and breathing and circulatory assessment whilst immobilising the head and neck in neutral alignment.

Figure 2. The rescuer must leave the head of the patient and kneel to the patient's side in preparation for turning the patient towards the rescuer. The patient's opposite leg is adducted across the nearest leg and the opposite arm is adducted across the body towards the rescuer.

Figure 3. The nearest elbow is then flexed and the hand placed under the head just above the ear ensuring minimal movement of the cervical spine.

Figure 4. The rescuer then grasps the patients opposite shoulder and pelvis.

Figure 5. Finally the patient is rolled towards the rescuer with the

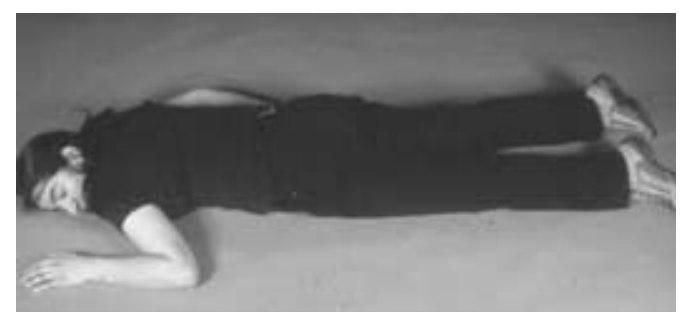

Fig 7.

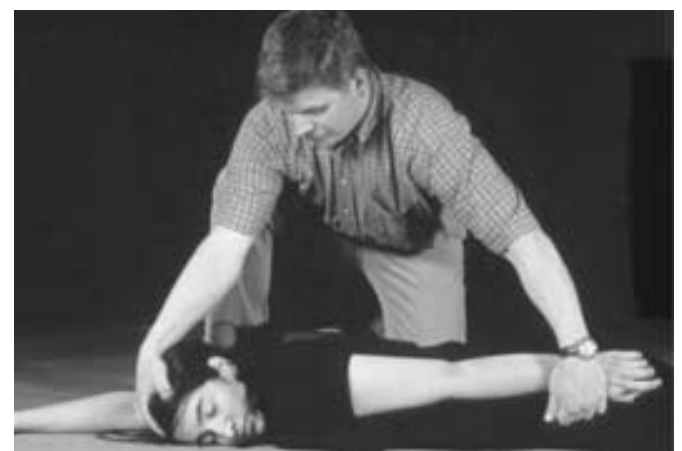

Fig 9.

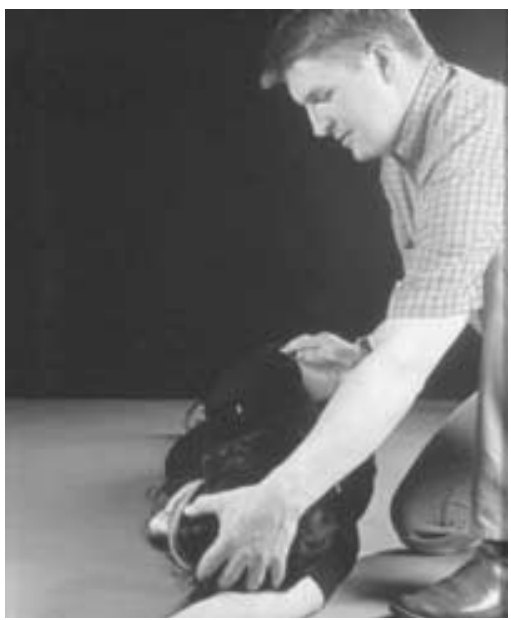

Fig 11 rescuer supporting some of the weight of the patient upon the rescuer's knees.

Figure 6. If the patient needs to be maintained in this position for a longer period of time, then the hand under the patient's head forms some support for the cervical spine.

\section{Method 2}

This technique is a modification of the HAINES position and is best used when starting with the patient in a prone position. Its use in this situation allows a patient to be turned safely for an initial survey of Airway, Breathing and Circulation.

Figure 7 . Starting position of patient.

Figure 8 . The rescuer kneels by the patient's side, the nearest arm is then abducted above the head. The patient's opposite leg is adducted across the nearest leg.

Figure 9. The opposite arm is brought

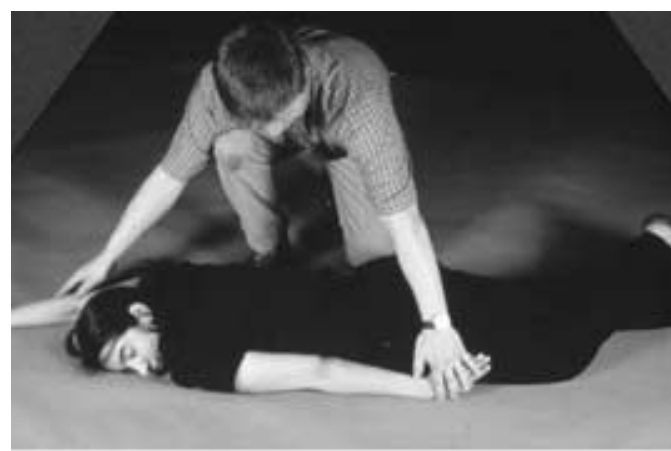

Fig 8.

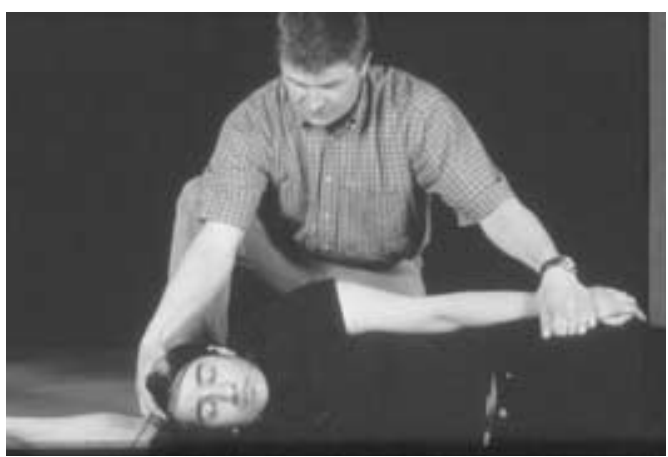

Fig 10.

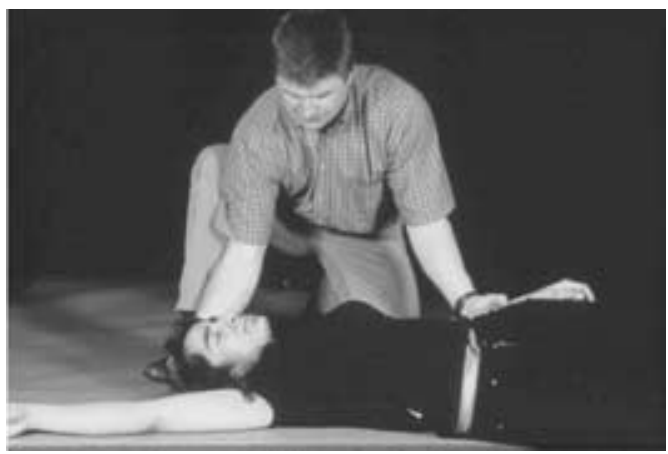

Fig 12 . 


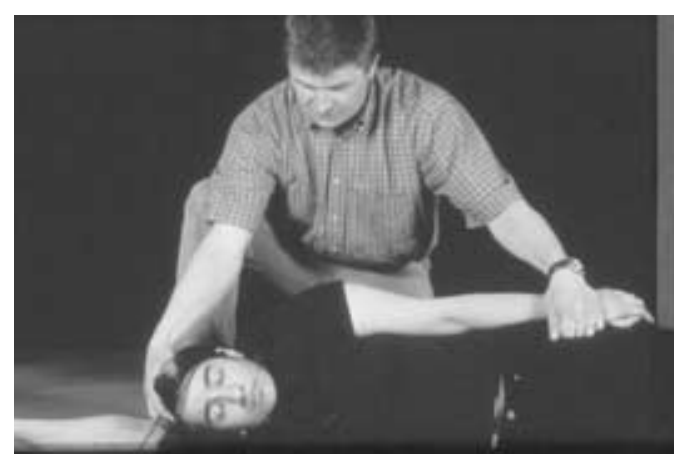

Fig 13.

down into the anatomical position. The rescuer then places one hand over the patient's opposite hand supporting the pelvis. The other hand is placed on top of the patient's head in order to control the movement of the head and neck.

Figures 10-13. The patient is then rolled towards the rescuer coordinating both hands to ensure the head is kept as near to neutral alignment as possible. The rescuer may roll the patient on to his knee in order to control the manoeuvre. If required, the patient can be turned into the supine position and manual in line stabilisation can then be applied once again.

\section{Discussion}

The pre-hospital management of any trauma victim involves the establishment of safety for the rescuer, the scene and the patient followed by a rapid primary survey of Airway (A), Breathing (B) and Circulation (C) (1) If these are deemed satisfactory at the time, Basic Life Support Guidelines suggest that in the unconscious patient should be placed in the recovery position to protect their airway and help prevent possible aspiration $(2,3)$. Unfortunately for the rescuer, current teaching suggests that all unconscious trauma patients should be presumed to have a cervical spine injury until proven otherwise, and there may not be an initial availability of personnel and equipment to log roll and immobilise the patient for transport to hospital.

The most commonly used recovery position (How position), advocated in the 1992 UK Resuscitation Guidelines was modified in the 1997 guidelines based on advisory statements issued by the International Liaison Committee on Resuscitation (ILCOR) $(2,4)$. There was much debate about the change, which was based on the potential dangers of reduced perfusion, neurapraxia and venous congestion in the dependant arm $(5,6)$. Doxey proposed that rescuers preferred the 1992 recovery position as it was easier to perform and more comfortable for the patient (7).

The HAINES position (High Arm IN Endangered Spine) was proposed in 1995 (8). In this position the patient's dependant upper limb is fully abducted, so as to lie under the head and reduce lateral flexion of the neck, and both lower limbs are flexed at the hip and knee aiming to reduce torque on thoracolumbar spine. The modified HAINES position places the uppermost upper limb longitudinally down the trunk rather than in front of the patient in order to further reduce thoracolumbar spine rotation. Blake et al proposed that the modified HAINES position resulted in a more neutral position of the spine with $13.0^{\circ}$ less lateral flexion and $12.6^{\circ}$ less extension of the cervical spine (9).

These two techniques are easy to learn and aim to minimise cervical spine movement in a trauma patient when the lone rescuer has no choice but to turn the patient in order to protect the airway. Scientific verification of the degree of movement is needed before these can be sensibly added to any national guidelines.

\section{References}

1. Basic Life Support. In Greaves I, Porter K, eds. Prehospital Medicine. The principles and practice of immediate care, pp 17-25. London: Arnold, 1999.

2. Turner S, Turner I, Chapman D, Howard P, Champion P, Hatfield J et al. A comparative study of the 1992 and 1997 recovery positions for use in the UK. Resuscitation 1998;39:153-60.

3. Resuscitation Council (U.K), Basic Life Support Resuscitation guidelines. http://www.resus.org.uk/

4. Handley AJ, Becker LB, Allen M, Van Drenth A, Kramer EB, Montgomery WH. Single rescuer adult basic life support. An advisory statement from the Basic Life Support Working Group of the International Liaison Committee on Resuscitation (ILCOR). Resuscitation 1997;34:101-8.

5. Rathgeber J, Panzer W, Gunther U, Scholz M, Hoeft $\mathrm{A}, \mathrm{Bahr} \mathrm{J}$ et al. Influence of different types of recovery positions on perfusion indices of the forearm. Resuscitation 1996;32:13-7.

6. Fulstow R,.Smith GB. The new recovery position, a cautionary tale. Resuscitation 1993;26:89-91.

7. Doxey J. Comparing 1997 Resuscitation Council (UK) recovery position with recovery position of 1992 European Resuscitation Council guidelines: a user's perspective. Resuscitation 1998;39:161-9.

8. Gunn BD, Eizenberg N, Silberstein M, McMeeken JM, Tully EA, Stillman BC et al. How should an unconscious person with a suspected neck injury be positioned? Prehospital. Disaster. Med. 1995;10:239-44. 9. Blake WE, Stillman BC, Eizenberg N, Briggs C, McMeeken JM. The position of the spine in the recovery position--an experimental comparison between the lateral recovery position and the modified HAINES position. Resuscitation 2002; 53:289-97. 